\title{
Die redaksionele geskiedenis van die boek Hosea
}

\author{
APB Breytenbach
}

\section{Abstract}

\section{The editorial history of the book Hosea}

It is the suggestion of this essay that the book of Hosea, was supplied with an introduction and ending by an editor from the wisdom circles. This thesis is based on the fact that Hosea 1: $2 a$ and 14: 10 correspond remarkably with the introductions and endings of Egyptian wisdom instructions (for instance that of Amenemopet). The absence of this kind of introductions and endings in other books of the Old Testament leads to the conclusion that the prophecies of Hosea found their way to Judah in the form of a complete book.

Daar word redelik algemeen aanvaar dat die boek Hosea, soos al die ander profeteboeke in die Ou Testament, in 'n mindere of meerdere mate redaksioneel bewerk is. Geleerdes verskil oor die vraag na die omvang van hierdie redaksionele arbeid aan die boek Hosea. Daar is wel redelike eenstemmigheid onder Ou-Testamentici dat die boek uiteindelik deur die hande is van die deuteronomistiese redaktor (of redaktore), wat verantwoordelik was vir die finale uitgawe van sommige van die profeteboeke. Dit word onder andere afgelei van die feit

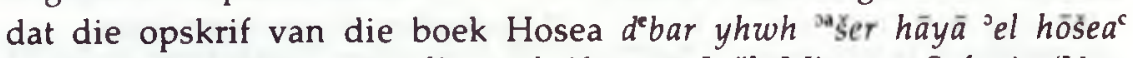
ooreenkoms vertoon met die opskrifte van Joël, Miga en Sefanja (Van der Woude 1977: 13). Alhoewel die geskiedenis van die opskrifte van profeteboeke en die redaksionele arbeid wat dit verteenwoordig, ingewikkelder is as wat algemeen aanvaar word (Oberholzer 1978: 70-80; Oberholzer 1985: 252-258), kan daar tog met redelike sekerheid aangeneem word dat die deuteronomistiese redaktor sy arbeid aan die boek Hosea, soos in die geval van Joël, Miga en Sefanja, verrig het gedurende of kort ná die Babiloniese ballingskap. Uit die feit dat die optrede van die profeet Hosea in die opskrif van die boek in die eerste plek gedateer word met behulp van die regeringstye van Judese konings, kan afgelei word dat die boek in sy finale vorm bedoel was vir Judese lesers. 
Sommige kommentatore meen dat die woorde $u b \bar{i} m \bar{e}$ yārob'ām ben$y \bar{o}^{-} \bar{a}$ š melek yiśrā'ẹl die oorblyfsels is van 'n ouer Israelitiese opskrif. Wolff (1961: 2) en Van Leeuwen (1968: 29) verbind hierdie woorde aan vers $2 a$ en veronderstel dat dit in die redaksionele geskiedenis van die boek aanvanklik net betrekking gehad het op die eerste periode van Hosea se optrede. Dit is egter meer waarskynlik dat die verwysing na 'n Israelitiese koning in die opskrif van die boek ook afkomstig was van die deuteronomistiese redaktor en dat dit nie bedoel was as datering nie, maar om vir die Judese lesers te sê dat Hosea in Israel opgetree het as profeet. ' $n$ Soortgelyke opskrif kom voor in Amos 1: 1 waar die profeet se optrede eers gedateer word vir Judese lesers deur 'n verwy. sing na 'n Judese koning, en daarna, deur 'n verwysing na 'n Israelitiese koning, dit duidelik gestel word dat Amos in Israel geprofeteer het.

In die boek Hosea is daar enkele byvoegings wat die hand van 'n Judese redaktor verraai. Alhoewel hierdie redaksionele byvoegings slegs sporadies voorkom, verteenwoordig dit waarskynlik verskillende stadia in die redaksionele geskiedenis van die boek. 'n Noukeurige ondersoek van gedeeltes waar na Juda verwys word in die boek, toon dat op grond van poëtiese en literêr-kritiese oorwegings, die volgende as redaksionele byvoegings beskou kan word (Breytenbach 1979: 14, $62-64,84-89,111,151)$ :

\section{Hosea 1: 7;}

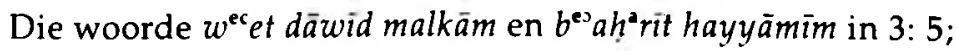

$y^{\prime} h \bar{u} d \bar{a}$ in $4: 15$.

kāšal gam-y $y^{\mathbf{e}} \bar{u}$ dā cimmām in 5: 5;

en gam-y'hūdā šât qāsî̀ läk in 6: 11.

Van hierdie gedeeltes is 1: 7 uniek in die sin dat dit, anders as in die ander gevalle, ' $n$ uitgebreide spreuk is en daarby ook veronderstel dat Juda ' $n$ vyandelike aanval op bonatuurlike wyse oorleef het. Saam met die meerderheid kommentatore kan aanvaar word dat hierdie ' $n$ redaksionele byvoeging is uit die tyd voor die Babiloniese ballingskap en dat dit waarskynlik verwys na die wonderbaarlike verlossing van Jerusalem uit die mag van Sanherib in 701 v C (vergelyk 2 Kon 19: 32-37).

Daarteenoor is die ander gedeeltes baie kort. Die invoegings in 3: 5; 5: 5 en 6: 11 veronderstel die Babiloniese ballingskap of die tyd kort daarna as agtergrond. In die geval van 5: 15 kan 'n beslissing moeilik geneem word. Dit sou ' $n$ invoeging uit die tyd voor of na die ballingskap kon wees. Soos dit tans daar staan, reflekteer dit in elk geval die 
sentimente van die deuteronomistiese kring wat sterk afwysend gestaan het teenoor die heiligdomme wat met Jerusalem meegeding het.

Die redaksionele byvoegings wat aan Judese redaktore toegeskryf kan word, is dus relatief min. Dit is waarskynlik gedoen in die tyd voor, gedurende en moontlik ook na die Babiloniese ballingskap. Dit verteenwoordig nie 'n pertinente ingrype in die teks nie, maar skep in die meeste gevalle die indruk van glosse wat later in die teks opgeneem is. Dit was kennelik bedoel om die profesieë van 'n Israelitiese profeet te aktualiseer vir die Judese lesers. Dit is waarskynlik gedoen deur redaktore uit đie deuteronomistiese kring en dit is moontlik dat 'n paar van die invoegings gedoen is deur dieselfde persoon of persone wat vir die opskrif van die boek verantwoordelik was.

Die boek Hosea het naas die deuteronomistiese opskrif in 1: 1 ook 'n ouer opskrif wat 'n pre-Judese fase van redaksionele arbeid reflekteer. Die woorde in Hosea 1: 2a naamlik $t^{\mathrm{e}}$ hillat dibber yhwh $b^{\mathrm{e}} h \overline{\mathrm{c}} \mathrm{s} e \mathrm{a}^{\mathrm{j}}$ het van die vroegste tye af aanleiding gegee tot misverstand. Die Joodse oorleweraars wat verantwoordelik was vir die samestelling en ordening van die Twaalfprofeteboek, het hierdie woorde klaarblyklik as 'n nominale sin verstaan wat soos volg vertaal kan word: 'Die begin van die spreke van JHWH was deur (middel van) Hosea.' Op grond hiervan is die boek Hosea eerste geplaas in die bundel van die Klein Profete. Rudolph verwys na gedeeltes in die Babiloniese Talmoed waarvolgens Hosea vroeër as Amos sou opgetree het (Rudolph 1966: 5). Daar word egter vandag redelik algemeen aanvaar dat Amos voor Hosea opgetree het as profeet. Moderne kommentatore meen weer dat Hosea 2: 1a (soos reeds gesê) verbind moet word met die laaste deel van Hosea 1: 1 . Dit is egter onbevredigend aangesien ' $n$ afgeronde eenheid (Hos 1: 1) sodoende opgebreek word en ' $n$ ouer teks waarvoor daar geen tekskritiese en weinig literêr-kritiese gronde bestaan, dan geponeer word.

Die oplossing van die probleem wat Hosea 1: $2 a$ bied, lê in 'n ander rigting. Professor JP Oberholzer het enkele jare gelede my aandag daarop gevestig dat die woorde t'hillat dibber yhwh merkwaardig ooreenkom met die inleidingswoorde van sommige Egiptiese wysheidsinstruksies. Dié wysheidsinstruksies, waarvan die meeste uit die tyd van die agtiende tot twintigste dinastie kom (1 500 tot $1100 \mathrm{v} \mathrm{C})$, begin feitlik deurgaans met die woorde: 'Die begin van die instruksie van A aan B' (Pritchard 1955: 414-420, vergelyk ook 431 en 432). Van besondere belang is egter die feit dat die instruksies of leerrede van Amenemope ook begin met die woorde 'Die begin van die onderrig ...' (Pritchard 1955: 421). Hierdie dokument is bekend daarvoor dat sekere dele 
daarvan en Spreuke 22: 17-24: 22 grootliks ooreenkom. Die datering van die leerrede van Amenemope is omstrede, maar daar kan met sekerheid aanvaar word dat dit êrens tussen die jare 900 tot $500 \mathrm{v} C$ geplaas moet word.

Van belang is ook die feit dat die leerrede van Amenemope (soos van die ander wysheidsinstruksies) eindig met ' $n$ verklaring oor die belang van die onderrig wat gegee is en die waarde wat dit het vir wie daarna luister. Die vertaling wat in Pritchard aangebied word van die genoemde dokument se slot, lui soos volg:

See thou these thirty chapters:

They entertain; they instruct;

They are the foremost of all books;

They make the ignorant to know.

If they are read out before the ignorant,

Then he will be cleansed by them.

Fill thyself with them; put them in thy heart,

And be a man who can interpret them,

Who will interpret them as a teacher.

Die opvallende is dat die boek Hosea ook eindig met 'n spreuk wat ongetwyfeld uit wysheidskringe afkomstig is (Hos 14: 10):

Wie wys is, sal op hierdie woorde ag slaan.-

Wie verstandig is, sal dit ter harte neem,

want wat die Here doen is reg.

Die regverdiges lewe daarvolgens,

maar die opstandiges kom daardeur tot ' $n$ val.

Hierdie spreuk is kennelik bedoel as ' $n$ slotwoord wat die belang en waarde van die voorafgaande onderrig beklemtoon. Wanneer 'n boek in die $\mathrm{Ou}$ Testament só voorsien is van ' $\mathrm{n}$ duidelike herkenbare inleiding en slot, kan daar geen twyfel daaroor wees dat 'n redaktor uit die wysheidskringe die boek Hosea op'n stadium hanteer het nie.

'n Noukeurige studie van die betrokke inleiding en slot van die boek Hosea het die volgende resultate opgelewer:

In die eerste plek kan gestel word dat hierdie inleiding en slot na alle waarskynlikheid nie afkomstig is van 'n Judese redaktor uit die tradisionele kringe in en om Jerusalem nie. Ons kan dit aflei uit die feit dat daar nêrens anders in die Ou Testament 'n soortgelyke inleiding voorkom nie. Daarby het latere J6odse oorleweraars klaarblyklik nie die 
presiese bedoeling van hierdie wysheidsinleiding begryp nie. Dit dui daarop dat dit literêr vreemd was vir die tradisionele oorleweringskring in Jerusalem.

In die tweede plek sluit die slot (Hos 14: 10), alhoewel dit in die idioom van die wysheid is, verrassend goed aan by die woordgebruik en woordinhoude van die profesieë in die boek Hosea. So byvoorbeeld het byn in vers 10a dieselfde betekenis as in 4: 14, naamlik 'ter harte neem'. $y d^{c}$ en $k s ̌ l$ is terme wat dikwels in die boek voorkom (vergelyk 4: $5 ; 5: 3-5 ; 14: 2$ ). Die feit dat $p s^{c}$ gebruik word as antoniem van șdq in vers 10 is ook veelseggend as die voorkoms van $p s^{c}$ in die profesieë in ag geneem word (vergelyk 7: 13 en 8: 1). In die tipiese wysheidsliteratuur kom $r \breve{s}^{\mathrm{c}}$ gewoonlik voor as antoniem van sidq.

Op grond van die voorafgaande kan die hipotese gestel word dat die redaktor uit die wysheidskringe wat die profesieë van Hosea van 'n inleiding en slot voorsien het, dit nie as los aanhangsels gedoen het nie, maar dat dit bedoel was as integrale deel van die boek.

Die feit dat ' $n$ redaktor uit die wysheidskringe die profesieë van Hosea redaksioneel versorg het, roep natuurlik 'n hele aantal vrae na vore:

In die eerste plek kom die vraag na die omvang van hierdie redaksionele arbeid by ' $n$ mens op. Het die redaktor net die inleiding en slot geskryf, of het hy ook van die materiaal in die boek op ' $n$ bepaalde wyse georden en dalk selfs uitgebrei? Hierdie vraag kan nie so maklik beantwoord word nie. Ou-Testamentici was aanvanklik oortuig daarvan dat die tipiese na-eksiliese skema van onheil gevolg deur heil ook in die boek Hosea voorkom (vergelyk Hos 1: 2-2: 3 (Hebreeus); 2: 4-25; 3: 1-5; 4: 1-14: 9). Huidiglik word egter meer algemeen aanvaar dat die plasing en ordening van profesieë in die boek Hosea gedoen is in ' $n$ oorleweringskring wat een of ander verband met die profeet gehad het. Daar word aanvaar dat die redaktor wat vir die grootste werk aan die boek verantwoordelik was, ook met 'n onheil-heil skema gewerk het (Kaiser 1978: 200). Hieroor kan die volgende opmerkings gemaak word: Daar is geen dwingende rede om 'n ordeningsprinsipe van onheil en heil as hipotese te aanvaar nie. Die profeet Hosea het aan die begin van sy optrede klaarblyklik die oordeel van God primêr uitgespreek oor die regering en oor Israel as staat. JHWH se verbond met Israel, die tienstammeryk, was verbreek (Hos 1: 9), maar dit het nie beteken dat die beloftes van JHWH aan die aartsvaders verval het nie (Hos 2: 1-3). Dit verklaar die dialektiese spanning tussen onheil en heil in die eerste hoofstukke van die boek. Die hele saak word trouens 
in Hosea 3: 1-5 saamgevat wanneer die vernietiging van die regering en kultus gesien word as voorwaarde vir die heil wat aan die $b^{\mathbf{e}} n \bar{e}$ yiśräel belowe word. Iets van dieselfde aard kom ook vanaf Hosea 11 tot 14 voor waar die profeet God se oordeel oor die hele volk aankondig, maar waar hy dan tog ook 'n herstel, gegrond op God se liefde en genade, wat ná die komende katastrofe sal volg, verkondig.

'n Noukeurige studie lei tot die konklusie dat die profesieë van Hosea in die boek breedweg chronologies gerangskik is (Breytenbach 1979: 372). Die implikasie hiervan is dat die persoon wat verantwoordelik was vir die saambundeling van die profesieë van Hosea, nie ver verwyder kon wees van die profeet nie. Oor die vraag of dit die wysheidsredaktor was, kan daar maar net bespiegel word.

Wolff (1961: XXIII-XXVII) meen dat daar drie oorspronklike oorleweringskomplekse in die boek onderskei kan word, naamlik Hosea 1: 2-3: 5 (1: 7 uitgesluit), 4: 1-11: 11 en 12: 1-14: 9. Wolff voer onder andere geringe stylverskille tussen dié eenhede aan as begronding van sy hipotese. Hierdie drie vermeende eenhede sluit egter inhoudelik so nou by mekaar aan (Breytenbach 1979: 91, 333), dat 'n onafhanklike bestaan van die drie eenhede baie onwaarskynlik is. ' $n$ Mens moet jou dit eerder so voorstel dat geringe verandering van styl en inhoudelike beklemtoning in die boek (wat nie noodwendig met die driedeling van Wolff saamval nie) eerder saamhang met verandering en ontwikkeling in die profetiese verkondiging. Hosea het immers vir ongeveer vyf en twintig jaar die wisselvallige geskiedenis van Israel begelei met sy prediking.

'n Ander vraag wat opgeroep word deur die feit dat 'n redaktor uit die wysheidskringe die profesieë van Hosea redaksioneel versorg het, is naamlik wat die verband was tussen die profeet en die wysheidskringe. Daar word redelik algemeen aanvaar dat daar invloed van die 'wysheid' in die boek Hosea voorkom (Wolff 1961: XV). Die volgende is voorbeelde daarvan (Breytenbach 1979: 367): In die eerste plek kom daar 'n oorvloed vergelykings en metafore in die boek voor. (Vergelyk byvoorbeeld Hosea 5 : 10-15; 7: 3-12; 9: 10-16; 10: 1-8, 11-13; 11: $1-4 ; 12: 14 ; 13: 2-8 ; 14: 6-9)$. Dit is 'n tipiese trek in die wysheidsliteratuur om lewenswaarhede deur middel van vergelykings en metafore aan die hoorders oor te dra. Daarmee hang ook die voorkoms van stylelemente soos die kettingspreuk in Hosea 2: 23-24 saam. In die tweede plek is daar soms merkwaardige ooreenkomste tussen die taalgebruik in die boek Hosea en dié in wysheidsliteratuur. Die volgende woorde het in die boek Hosea die betekenisnuanses wat dit elders in 
die Ou Testament slegs in wysheidsboeke het: hepess in 8: 8 (vergelyk Spr 3: 15; 8: 11) en $q^{\mathrm{e}}$ dōšm as aanduiding van God in 12: 1 (vergelyk Spr 9: 10). Die gebruik van die woord rūah in beeldspraak waar dit gaan oor nietigheid $(8: 7 ; 12: 2)$ is ook tipies van wysheidsliteratuur. In die derde plek is daar sekere inhoudelike verbande wat in die boek Hosea gelê word, wat ooreenkom met inhoudelike verbande wat in die wysheidsliteratuur gelê word. Dit geld byvoorbeeld vir die verband tussen goddeloosheid en dwaasheid (Hos 7: 9-11; 13: 12-13) en in ' $n$ mindere mate ook vir die verband tussen daad en gevolg. Die voorafgaande voorbeelde sou uitgebrei kon word. Die belangrike is dat hierdie voorbeelde van invloed van die wysheid, verspreid voorkom in die hele boek en dat dit 'n inherente deel uitmaak van die profesieë. Dit kan alleen beteken dat die profeet na alle waarskynlikheid self verbintenisse gehad het met of deel was van groepe wat as die wysheidskringe bekend staan.

Daar is ook nog ander vrae wat na vore kom as die redaksionele arbeid aan 'n profeteboek deur iemand uit die wysheidskringe in ag geneem word. So byvoorbeeld sou dit insiggewend wees om die verband tussen die boek Hosea en protodeuteronomistiese gedeeltes wat ook wysheidsinvloed verraai, na te gaan (vergelyk byvoorbeeld Deut 32: 39 met Hos 5: 14; 6: 1). Dieselfde geld ook vir die vraag na die moontlike verband tussen wysheidskringe en groepe vir wie die verbond van JHWH met Israel ' $n$ dominante teologumenon was. Die bestek van hierdie artikel laat so 'n ondersoek egter nie toe nie.

Ons moet ons die redaksionele geskiedenis van die boek Hosea soos volg voorstel:

Die eerste optekening van profesieë is waarskynlik deur die profeet of ' $n$ onmiddellike volgeling gedoen. In die eerste plek kan dit afgelei word uit die gebruik van die eerste persoon in Hosea 3: 1-4. In die tweede plek moet daarmee rekening gehou word dat 'n profesie in die meeste gevalle 'n stuk poësie is wat deur'n digter-profeet gedig word. Dit is waarom dit byvoorbeeld vir'n profeet soos Jeremia moontlik was om in die tyd van koning Jojakim nog profesieë te kon dikteer wat hy ongeveer twintig jaar tevore uitgespreek het (Jer 36: 1-32). Sulke gedigte is nie impromptu voorgedra nie, maar vooraf saamgestel. 'n Profesie is gewoonlik ook nie net een maal voorgedra nie, maar meestal by meer as een geleentheid. Dit is in die lig hiervan nie onwaarskynlik nie dat ' $n$ profesie selfs voordat dit in die openbaar voorgedra is, reeds op skrif gestel is. Die literêre kwaliteit van die gedigte in die boek Hosea dui daarop dat dit waarskynlik van die begin af op skrif gestel is. In die derde plek skep 'n gedeelte soos Hosea 9: 7b, waarin die reaksie van 
die volk op Hosea se prediking verwoord word, onvermydelik die indruk dat sy profetiese werksaamheid baie gou te boek gestel is.

Die profesieë is waarskynlik algaande in volgorde opgeteken. Ons kan dit aflei uit die breë chronologiese ordening van profesieë in die boek. Daar het waarskynlik dus mettergaan 'n bloemlesing van profetiese Hosea-gedigte ontstaan. Dit verklaar myns insiens die afwesigheid van verbindende vertellings en agtergrondgegewens in die boek.

Op ' $n$ bepaalde stadium is daartoe oorgegaan om van die profetiese uitsprake en gedigte ' $n$ afgeronde stuk skriftelike verkondiging te maak. Dit is moontlik dat die profeet dit deels self gedoen het. Dit is meer waarskynlik dat ' $n$ volgeling of volgelinge dit gedoen het. Dit is ook moontlik dat daarmee reeds begin is op ' $n$ vroeë stadium. Dit is meer waarskynlik dat dit ná die dood van die profeet gedoen is deur volgelinge. Die algemene indruk wat ' $n$ mens $k r y$ is dat hierdie deel van die literêre geskiedenis meer redaksioneel van aard was. Die persoon of persone wat dit gedoen het, het dus nie die profesieë van Hosea werklik uitgebrei nie. Daar is waarskynlik net aanvullings en moontlik ook geringe herrangskikkings gedoen.

Hierdie proses van redaksionele arbeid is afgesluit met die aanbring van die wysheidsinleiding en slot. Die persoon wat dit gedoen het, was waarskynlik (soos reeds gesê) uit dieselfde kringe as die profeet en sy volgelinge afkomstig. Dit is ook moontlik dat hierdie bydrae deel was van breër literêre aktiwiteite in die Israelitiese gebied na die val van Samaria. Dit het waarskynlik, anders as in Juda, buite die kringe van die amptelike kultus plaasgevind by bepaalde intellektuele groepe wat die Jahwisme aangehang het. (Die werk van Whybray 1974 is in dié verband relevant.)

Die profesieë van Hosea het dus in die vorm van 'n afgeslote boek hulle pad na Juda gevind teen die einde van die agste eeu, waarskynlik in die tyd van koning Hiskia. Die redaksionele bydrae van Judeërs tot die huidige boek Hosea was gering. Soos reeds gesê, was dit persone uit die deuteronomistiese kring was naas die opskrif van die boek, in enkele gevalle by wyse van glosse, die prediking van Hosea vir Judese lesers geaktualiseer het. Die verwysing na Hosea as die seun van Beëri in die opskrif is waarskynlik ook die werk van 'n Judese redaktor. Uit Jeremia 26: 17-19 weet ons dat die naam van 'n profeet en die belangrikste aspekte van sy verkondiging, ook mondeling oorgelewer is. Die verwysing na Hosea as die seun van Beëri is waarskynlik 'n oorblyfsel van die mondelinge oorlewering wat die profesieë van Hosea begelei het. 
Met hierdie artikel bring ek graag hulde aan professor JP Oberholzer. Hy stel nie net self baie belang in die redaksionele geskiedenis van die profeteboeke nie, maar sy opmerking oor die ooreenkoms tussen Hosea 1: 2a en die inleidingswoorde van Egiptiese wysheidsinstruksies was die direkte stimulus vir my siening oor die redaksionele geskiedenis van die boek Hosea.

\section{Literatuurverwysings}

BREYTENBACH, APB 1979. Die verband tussen en die ontwikkeling in die profetiese uitsprake in die boek Hosea. DD-proefskrif, Universiteit van Pretoria.

KAISER, O 1978. Einleitung in das Alte Testament. Gütersloh: Gerd Mohn.

OBERHOLZER, JP [1978]. Die opskrifte in die profeteboeke, l. HTS 34/4, 70-80.

OBERHOLZER, JP 1985. Die opskrifte in die profeteboeke, II. HTS 41/2, 52-259.

PRITCHARD, JB (ed) 1955. Ancient Near Eastern texts relating to the Old Testament. Princeton: Princeton University Press.

RUDOLPH, W 1966. Hosea. Gütersloh: Gerd Mohn. (Kommentar zum Alten Testament.)

VAN DER WOUDE, AS 1976. Micha. Nijkerk: Callenbach. (De Prediking van het Oude Testament.)

VAN LEEUWEN, C 1968. Hosea. Nijkerk: Callenbach. (De Prediking van het Oude Testament.)

WHYBRAY, RN 1974. The intellectual tradition in the Old Testament. Berlyn: De Gruyter. (BZAW.)

WOLFF, HW 1961. Dodekapropheton I, Hosea. Neukirchen: Neukirchener Verlag. (BK AT.) 